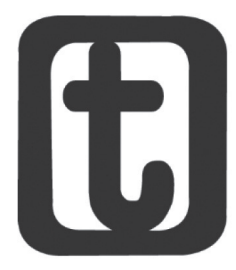

\title{
CONTRIBUIÇÃO DA ABEPSS PARA O FORTALECIMENTO DOS PROGRAMAS DE PÓS- GRADUAÇÃO EM SERVIÇO SOCIAL NO BRASIL'
}

The contribution of ABEPSS to the strengthening of post-graduate programmes in Social Service in Brazil

\section{INTRODUÇÃO}

A Associação Brasileira de Ensino e Pesquisa em Serviço Social (ABEPSS) (gestões 2013-2014 e 2015-2016), por meio deste documento, apresenta subsídios/referências à Pós-Graduação em Serviço Social no Brasil, visando contribuir com o fortalecimento dos Programas dos cursos stricto sensu na área, e também da própria ABEPSS, como associação acadêmico-científica, tornando a Pós-Graduação mais orgânica nesta relação. Neste sentido, cumpre com as atribuições estatutárias que competem à Coordenação Nacional de Pós-Graduação, especialmente no que diz respeito à consolidação e qualificação do Serviço Social como área de conhecimento.

Este documento resultou originalmente da sistematização das discussões realizadas pelo Grupo de Trabalho sobre Pós-Graduação/ ABEPSS $^{2}$ nos anos de 2013 e 2014, com a incorporação de sugestões

1 Esta versão do documento possui as contribuições da reunião do Fórum Nacional de Coordenadores de Pós-Graduação da ABEPSS realizada em 03 de novembro de 2015 .

2 Este grupo de trabalho foi criado a partir das demandas postas à gestão da ABEPSS (2013-2014) na primeira reunião com os Coordenadores dos Programas de Pós-Graduação em Serviço Social no Brasil, em junho de 2013, na Universidade Federal do Espírito Santo (Ufes). É formado por docentes dos Programas de Pós-Graduação de várias universidades e regiões do país, os quais têm historicamente dado contribuição à pós-graduação na área e à ABEPSS, a saber: Reivan Souza (UFAL), Yolanda Guerra (UFRJ), Maria Carmelita Yazbek (PUC-SP), 
dos programas da área no Fórum Nacional de Pós-Graduação na Oficina Nacional da ABEPSS, realizada em Goiânia, em dezembro 2013. Em 2015, objetivando ampliar e adensar as discussões sobre a esfera da pós-graduação expressas neste documento, o Fórum Nacional de Coordenadores de Pós-Graduação da ABEPSS, reunido em novembro daquele ano, se debruçou coletivamente sobre os aspectos apresentados, possibilitando seu aprofundamento, cujos resultados já se encontram inseridos na atual versão do documento.

Deste modo, trata-se, portanto, de um documento sistemático da entidade dirigido exclusivamente ao universo stricto sensu ${ }^{3}$, que deve ser continuamente debatido entre os diversos sujeitos que constroem os Programas de Pós-Graduação em todo o país, na perspectiva de criar indicativos coletivos para enfrentar os desafios à pós-graduação na área de Serviço Social.

Podemos afirmar que o Serviço Social alcança sua maioridade acadêmica, inscrevendo-se como área de conhecimento em meados dos anos de 1970, quando então emerge e se estrutura a Pós-Graduação no Brasil. Antes disso, há uma longa trajetória histórica profissional orientada por um projeto de formação acadêmica tradicional e de produção de conhecimentos que priorizava a dimensão técnica-operativa, com base no positivismo e no funcionalismo, herdeiros do legado do Serviço Social estadunidense, conforme está expresso nas publicações que marcaram os anos de 1940 até 1960. Este projeto de formação de base tradicional só será questionado nos idos de 1965 a 1975 com o protagonismo do Movimento de Reconceituação latino-americano; este inaugurou, com suas referências críticas, o debate teórico e o incentivo à qualificação acadêmica e à pesquisa, expressando a primeira articulação em torno de um projeto de formação profissional crítico. Deste movimento resultou a formação do

Elaine Behring (UERJ), Silvana Mara (UFRN), Ivanete Boschetti (UnB), Nádia Fialho (UFPA), Angela Amaral (UFPE). O grupo realizou reuniões em outubro de 2013, na UFRN, Natal (RN), e em agosto de 2014, na UFRJ, Rio de Janeiro (RJ), organizadas pela Coordenação Nacional de Pós-Graduação e Presidência da ABEPSS, respectivamente, Reivan Souza e Regina Ávila.

3 Reflexões importantes sobre a Pós-Graduação no Brasil foram realizadas historicamente por intelectuais de Serviço Social nos programas, por gestões anteriores da ABEPSS e por representantes de área na CAPES e no CNPq 
Centro Latino-Americano de Trabalho Social (CELATS) ${ }^{4}$, que congregou, na América Latina, um número significativo de publicações na área, com investigações sobre os fundamentos histórico-metodológicos do Serviço Social. Destaque-se, nesse período, o legado acadêmico e político da Associação LatinoAmericana de Escolas de Trabalho Social (ALAETS), atualmente, Asociación Latinoamericana de Enseñanza e Investigación en Trabajo Social (ALAEITS), que contribuiu para a articulação de um projeto profissional crítico no Serviço Social latino-americano.

Uma das expressões da articulação desse projeto de formação profissional entre os anos de 1970 e 1980 e que perdura até os dias atuais, principalmente no Brasil, está, conforme destaca Yazbek (2008), no modo como

o Serviço Social brasileiro vem dialogando e se apropriando do debate intelectual contemporâneo noâmbito das Ciências Sociais [no] país e [no] exterior. Também a partir daí o Serviço Social desenvolveu na pesquisa sobre a natureza da sua intervenção, de seus procedimentos, de sua formação, de sua história e, sobretudo, acerca da realidade social, política, econômica e cultural onde se insere como profissão na divisão social e técnica do trabalho. Avanços na compreensão do Estado capitalista, das políticas sociais, dos movimentos sociais, do poder local, dos direitos sociais, da cidadania, da democracia, da realidade institucional e de outros tantos temas sobre os quais recaem seus objetos profissionais. [...]. Obteve o respeito de seus pares no âmbito interdisciplinar e alcançou visibilidade na interlocução com as ciências humanas, apesar das dificuldades decorrentes da falta de experiência em pesquisa, do fato de se defrontar com restrições por se constituir em disciplina interventiva ("Ciências Sociais Aplicadas", segundo as agências de fomento) e das dificuldades na apropriação rigorosa das teorias sociais (YAZBEK, 2008, p. 20).

Na continuidade deste processo, cumpre salientar que é nos anos de 1980, momento de expansão da pesquisa no Serviço Social, que

\footnotetext{
${ }^{4}$ O CELATS foi criado em 1977, caracterizado como braço acadêmico da Associação Latino-Americana de Escolas de Serviço Social (ALAETS), e teve importante contribuição no fortalecimento da pós-graduação na América Latina (ABEPSS, 2003).
} 
entidades como a então Associação Brasileira de Escolas de Serviço Social (ABESS) $)^{5}$ e, principalmente, o Centro de Documentação e Pesquisa em Políticas Sociais e Serviço Social (CEDEPSS) realizaram encontros de pesquisas e de pesquisadores, apoiando as iniciativas das universidades em criar os Programas de pós-graduação, com cursos stricto sensu e lato sensu, em Serviço Social no Brasil. Intentaram superar uma marca histórica - tecnicista/pragmática/ instrumental - que dificultava o aprofundamento teórico da relação entre práticas profissionais e realidade social. Avança-se em termos da laicização profissional e consolida-se a carreira docente na pós-graduação. Nesta década consolida-se a perspectiva crítica marxista, expressa na "[...] direção social estratégica da profissão [...]" (NETTO, 1996), no processo de renovação profissional ${ }^{6}$. É com a afirmação da perspectiva de Intenção de Ruptura, no interior da universidade brasileira, que o Serviço Social constrói, teórica e metodologicamente, a crítica aos projetos de sociedade e de formação profissional de base conservadora, a partir da assimilação da teoria social de Marx. Segundo o autor, a importância desse processo é que

[...] ao projeto de ruptura impunha-se um formidável trabalho teórico-metodológico. Tratava-se tanto da crítica aos substratos do tradicionalismo quanto da apropriação de um arcabouço diferente - e isto, recorde-se, numa profissão desprovida de acúmulo no domínio da elaboração e da investigação; nem mesmo uma eventual recuperação dos vetores críticos do passado recente aportaria aqui contributo de vulto. $\mathrm{E}$ a tarefa era hercúlea na medida em que deveria remar na contracorrente das direções ideais dominantes na vida brasileira. De outra, e também à diferença das demais vertentes renovadoras, cabia encontrar formas e modos de experimentação para as propostas interventivas decorrentes do novo embasamento teórico-metodológico (NETTO, 2007, p. 249).

5 Transformada em Associação Brasileira de Ensino e Pesquisa em Serviço Social (ABEPSS) em 1998, na Assembleia Nacional da entidade que aprovou o novo estatuto.

6 O processo de renovação profissional inicia-se, no Brasil, com a perspectiva de Intenção de Ruptura, nos idos de 1980, mediante a construção do Projeto Ético-Político Profissional que aglutina segmentos da categoria em torno dos interesses da classe trabalhadora e da superação da sociabilidade capitalista. 
O avanço da formação profissional em nível de pós-graduação, desde os anos de 1980, evidencia-se na expressiva produção teórica do Serviço Social brasileiro, que vem gerando uma bibliografia consistente, crítica, vasta, plural e contemporânea, resultante da consolidação dos programas de pós-graduação, em que amadurecem as pesquisas em nível de Mestrado e de Doutorado, bem como a estruturação dos grupos, núcleos e redes de pesquisa nas unidades de formação acadêmica/UFA.

Da estruturação desses grupos surge, a partir dos debates nos Encontros Nacionais de Pesquisadores em Serviço Social, os Grupos Temáticos de Pesquisa (GTPs) ${ }^{7}$, criados em 2010 pela ABEPSS, os quais buscam articular e impulsionar as experiências de pesquisa e a produção acadêmica. Isso demonstra o esforço de um conjunto representativo de docentes, discentes e pesquisadores na universidade brasileira para consolidar o Serviço Social como área de conhecimento.

Nesse processo, não há como negar os avanços alcançados pelo Serviço Social brasileiro na formação profissional em nível de pós-graduação e de graduação ${ }^{8}$. No entanto, o contexto de crise estrutural $^{9}$ no capitalismo e de seu processo de reestruturação

7 Os GTPs são formados por pesquisadores de temáticas específicas que constituem subáreas ou especialidades de conhecimento do Serviço Social. Constituem-se como órgãos de apoio acadêmico-científico da ABEPSS, previstos em seu Estatuto desde 10/12/1998. Atualmente são sete GTPs, a saber: Trabalho, Questão Social e Serviço Social; Política Social e Serviço Social; Serviço Social: Fundamentos, Formação e Trabalho Profissional; Movimentos Sociais e Serviço Social; Questões Agrária, Urbana, Ambiental e Serviço Social; Serviço Social, Relações de Exploração/Opressão de Gênero, Raça/Etnia, Geração, Sexualidades; Ética, Direitos Humanos e Serviço Social.

${ }^{8}$ O projeto de Reforma do Currículo Mínimo do Serviço Social no Brasil, em 1982, e as Diretrizes Curriculares da ABEPSS, aprovadas em 2006, expressam historicamente o avanço da profissão em termos da formulação de um projeto de formação profissional crítico, comprometido com as demandas de reprodução material e social da classe trabalhadora. Esses dois documentos contribuíram decisivamente para o avanço da pós-graduação em Serviço Social.

9 Mészáros (2002), em sua grande obra, explica que a crise estrutural é de natureza global e profunda porque afeta a gênese do sistema sociometabólico do capital desde os anos de 1970. Considera que, após períodos de expansão/ prosperidade e de depressão, o capital é marcado pela continuidade depressiva, o que evidencia o seu caráter sistêmico e estrutural. Salienta que a crise possui quatro elementos que a distinguem das demais crises que aconteceram no capitalismo: 1. O caráter não restrito a uma determinada esfera da economia, pois atinge o cerne do sistema sociometabólico do capital - produção, consumo 
atual requisita uma apreensão crítica das mudanças nos processos de trabalho, da inserção da profissão na divisão do trabalho, de seus vínculos com o real, das alterações na esfera do Estado, das políticas sociais e dos direitos, além dos posicionamentos políticos que segmentos da profissão imprimem aos projetos profissional e societário. Nesse contexto de alterações societárias, nos anos de 1990/2000, resultante do movimento que as classes realizam, “[...] surgem novas exigências às práticas profissionais, aos processos da formação profissional e à organização dos sujeitos da profissão" (KOIKE, 2009, p. 1).

Os desafios na atualidade são, portanto, inúmeros, dentre eles os impactos da contrarreforma universitária brasileira ${ }^{10}$ no contexto da reestruturação capitalista. Esta estabelece diretrizes e metas coerentes com os interesses do projeto mercantil do grande capital na esfera da educação. A política de educação no ensino superior representa uma verdadeira contrarreforma da universidade pública, pois "[...] agrava a condição capitalista dependente do país e aprofunda a heteronomia cultural vis-à-vis aos países centrais" (LEHER, 2004, p. 13). Isso explica porque a reforma universitária

e circulação; 2. A amplitude global da abrangência; 3. O caráter não dramático da queda na produção, mas determinado por um crescimento débil e rastejante; e, por fim, 4. A continuidade/extensão de seu tempo. Esses quatro aspectos compõem o quadro do colapso estrutural, atingem o cerne da reprodução do capital (produção, consumo e circulação) e se manifestam para além da esfera financeira, com consequências para a humanidade em diversas esferas da sociabilidade. Suas expressões mais agudas são: intensa exploração no trabalho, desemprego estrutural, agravamento da questão ambiental (caráter destrutivo da natureza), o dilaceramento das relações humanas (agravamento da pobreza) e a precarização das condições de trabalho e da reprodução social. Para responder às consequências dessa crise, o capital vem adotando práticas de reestruturação capitalista.

${ }^{10} \mathrm{O}$ ideário da Reforma Universitária brasileira, produzido num momento de democratização do país, consolida-se através da reorientação dos fundamentos que sustentam a crítica ao chamado modelo europeu de universidade, realizado pelo BM e pelos teóricos da Escola de Chicago (Friedman e Gary Backer), ideólogos do projeto neoliberal. É então o Núcleo de Pesquisa do Ensino Superior da USP o principal centro difusor de tal pensamento no Brasil, o qual reúne professores e dirigentes universitários como Eunice Durham, Simon Schwartzman e José Goldemberg, entre outros. Isso comprova a afinidade entre os organismos internacionais e a política educacional brasileira, quando redimensiona essa política para operar a expansão da esfera privada em detrimento da pública. Confirma-se tal orientação quando se destaca que "[A] reforma não é somente de estrutura pública, é uma reforma da relação público-privada a partir do critério do interesse público" (HASHIZUME, 2004 apud LEHER, 2004, p. 20). 
não é apenas “[...] uma política de um ministério, mas uma política de governo que está inserida num projeto mais amplo de educação e de sociedade" (LIMA, 2004, p. 23). Expressa um projeto de sociedade que tem como finalidade

[...] manter a coesão social que garanta a 'governabilidade' das classes dominantes e [aprofunde] o processo de privatização de setores estratégicos nos países periféricos (educação, ciência e tecnologia, telecomunicações etc.), áreas de interesse do capital internacional na busca de novos campos de exploração lucrativa na divisão internacional do trabalho (LIMA, 2004, p. 28).

A nova proposta para o ensino superior brasileiro sofre influência do

Protocolo de Bolonha, acordo firmado entre 29 países europeus, no ano de 1999, para padronizar o ensino superior nestes países, que tem trazido mudanças significativas [...] no que se refere à redução do tempo de formação e titulação e à constituição de um perfil de trabalhador funcional às demandas do mercado (GUERRA, 2012, p. 1).

Isso implica, nos países da periferia do capitalismo, formação profissional aligeirada, o que rompe com o princípio da indissociabilidade entre ensino, pesquisa e extensão, tornando as universidades suscetíveis ao acesso e à reprodução do conhecimento fragmentado/fraturado da realidade e da profissão.

Nesse contexto, o Plano Nacional de Pós-Graduação"11 (PNPG) (20112020) ${ }^{12}$, uma das diretrizes da reforma do ensino superior para a

11 Os cinco Planos Nacionais de Pós-Graduação, elaborados no Brasil, apresentaram diretrizes e propostas para viabilizar a pós-graduação e a pesquisa e, em geral, articulam-se às projeções do Estado para incrementar a Política de Ciência e Tecnologia. O PNPG atual, formulado por uma comissão orientada pela CAPES, em 2010, "[...] dá continuidade aos cinco [planos] anteriores e introduz novas e importantes inflexões" (PNPG, 2010, p. 16). Este plano foi o primeiro plano contemplado no Plano Nacional de Educação (PNE) e visa qualificar docentes do ensino superior e da educação básica para responder tecnicamente às demandas do setor produtivo industrial e de serviços. O documento enfatiza ainda o investimento de recursos na pós-graduação brasileira na área da Ciência e Tecnologia (Engenharias), justificando que nos planos anteriores os recursos destinaram-se, na sua maioria, a subsidiar os programas nas áreas das Ciências Humanas, Sociais, Letras e Artes, e de Saúde e Biologia. Uma justificativa que mascara a verdadeira finalidade do plano.

12 Simon Schwartzman (2010, p. 17) escreve um texto que visa subsidiar a 
pós-graduação, em vigor no Brasil, está fundamentado na gestão empresarial orientada às exigências da produção econômica. Conforme é ressaltado no documento:

O país entrou no século XXI como uma nova potência emergente, com a perspectiva de tornar-se a quinta economia do planeta no decênio 2011-2020. Tratase de um fato extraordinário, revelando que o país vem passando e deverá passar mais ainda por mudanças profundas em segmentos importantes da economia, com reflexos na geopolítica mundial e impactos em diferentes setores da sociedade, inclusive no sistema educacional, aí incluído o ensino superior (PNPG, 2010, p. 16).

Sobre esses aspectos, que reafirmam os fundamentos contidos no PNPG (2005-2009), Amaral (2012) esclarece:

Os argumentos justificadores dos formuladores do novo Plano reafirmam as balizas do anterior no sentido de invocar o papel que o Brasil terá no cenário internacional, com destaque para o lugar que o país ocupará como celeiro agrícola e como grande exportador de bens industriais. Faz-se, ainda, referência aos padrões demográficos do Brasil, os quais, aproximadamente, serão similares aos da Europa e da América do Norte, proporcionando

elaboração deste plano decenal e faz uma avaliação negativa da pós-graduação brasileira e da produção de conhecimento nas diversas áreas. Considera que a maioria dos cursos de Mestrado e de Doutorado acadêmicos centra-se no desempenho acadêmico e não nas demandas do mercado, fato que não contribui, segundo ele, para fortalecer o projeto de pós-graduação da maioria das instituições de ensino superior, que são privadas. Seus argumentos estão, a nosso ver, explicitados sinteticamente na seguinte afirmação: "Tomados em seu conjunto, estes dados mostram que a pós-graduação brasileira, ao dar prioridade ao desempenho acadêmico, através de um conjunto de instrumentos de regulação legal, incentivos fiscais e mecanismos de avaliação, acabou criando um sistema cuja função principal é se autoalimentar e que, com as exceções de sempre, nem consegue produzir uma ciência de padrão internacional, nem consegue gerar tecnologia para o setor produtivo, nem consegue dar prioridade aos que buscam formação avançada para o mercado de trabalho não acadêmico. O fato de que a maioria dos doutores trabalhe em universidades não é em si uma anomalia, já que o setor educativo necessita de pessoas bem qualificadas que possam ajudar na formação de novas gerações. Mas as instituições privadas, onde $77,5 \%$ de estudantes de nível superior estão matriculados, dificilmente podem contratar professores com regime de dedicação completa, o que leva a que os benefícios da pós-graduação acabem ficando muito restritos" (SCHWARTZMAN, 2010, p. 17). 
aquilo que os demógrafos vislumbram como uma rara 'janela de oportunidade', ou, a 'janela de vencer nossas heranças social-históricas, pagar a dívida social e criar uma sociedade de bem-estar' (AMARAL, 2010, p. 233).

Dentreasprincipaisênfasese diretrizes ${ }^{13}$, oPNPG ${ }^{14}$ propõe:aformação de uma agenda nacional para a pós-graduação; ampliar o Sistema Nacional de Pós-Graduação (SNPG); reestruturar os processos de avaliação dos programas stricto sensu; incentivar a inovação; ampliar as fontes de financiamento da pós-graduação; combater as assimetrias regionais; enfatizar a nucleação dos cursos de pósgraduação via processos de inter(multi)disciplinaridade; incentivar a cooperação internacional; investir na formação de recursos humanos para as empresas e para atuar em programas nacionais (áreas de saúde, energia); investir e desenvolver tecnologias; induzir parcerias entre universidades e organizações do setor público e privado; incentivar a criação dos mestrados profissionalizantes ${ }^{15}$ etc.

Com essas ênfases e diretrizes do documento fica explícito o projeto de ampliação da formação de profissionais com o objetivo de produzir pesquisas que respondam prioritariamente às demandas

${ }^{13}$ Segundo expõe AMARAL (2012, p. 232), “A lógica de organização do 5. ou 6. Plano Nacional de Pós-Graduação é orientada pela definição de cinco eixos. O primeiro refere-se à expansão do Sistema Nacional de Pós-Graduação (SNPG), cujas ênfases são 'a primazia da qualidade, a quebra da endogenia e a atenção à redução das assimetrias'. O segundo eixo orientador diz respeito à necessidade de criação de uma nova agenda nacional de pesquisa e sua associação com a pós-graduação. No terceiro, o destaque é dado para o aperfeiçoamento da avaliação e sua expansão para outros segmentos do sistema de Ciência, Tecnologia e Inovação 7. No quarto eixo, apresenta-se a multi e a interdisciplinaridade entre as principais características da pósgraduação e os importantes temas da pesquisa. Por último, expõe-se, como uma das diretrizes centrais do Plano, o apoio à educação básica e a outros níveis e modalidades de ensino, especialmente o ensino médio".

${ }^{14}$ Cf. CAPES (2010).

${ }^{15}$ Essa nova modalidade de cursos stricto sensu, os mestrados profissionalizantes, no Brasil, surge nos idos de 2009, expandindo-se em diversas áreas. Seu foco principal da formação é a qualificação técnica para o mercado de trabalho, e não formar pesquisadores conforme o Mestrado acadêmico. São eleitas áreas específicas do conhecimento, cuja formação instrumental/operativa deve melhorar a eficiência da atuação de profissionais nas organizações públicas e privadas, visando à solução dos problemas do país. Os estudantes desses cursos não são preparados para desenvolver a dimensão intelectual, mas apenas o domínio técnico (habilidades, aptidões) que corrija rápida e eficazmente "[...] o mau funcionamento da engrenagem capitalista" (GUERRA, 2012, p. 5). 
do setor produtivo industrial e do setor privado, facultando ao máximo a flexibilização dos cursos para acompanhar a produção de conhecimentos dos países de capitalismo central. A perspectiva desenvolvimentista orienta a nova lógica da pesquisa e da pósgraduação, haja vista estimular a articulação entre universidade/ conhecimento e desenvolvimento econômico para, supostamente, responder a um padrão de bem-estar social, pois “"[...] a agenda da universidade brasileira deve pautar o tema da pobreza, da inclusão, da exclusão social, da assistência estudantil, ao tempo que avançam processos de classificação da produção, de indicadores de citação internacional, de parâmetros avaliativos com base nas referências das consideradas maiores universidades do mundo" (AMARAL, 2012, p. 233). Tanto a universidade estará imitando os padrões das agências internacionais, como respondendo "[...] às demandas dos governos progressistas" (AMARAL, 2012, p. 233). Uma simbiose que atende às requisições dos organismos multilaterais.

Este Plano, regulamentado pela Lei de Inovação Tecnológica, pretende superar a defasagem da pós-graduação brasileira em relação aos países centrais. A "[...] Lei de Inovação Tecnológica" [...] busca promover a inovação por meio da articulação entre os diversos setores, visando uma maior interação universidade/ empresa e a participação de pesquisadores no desenvolvimento de novas tecnologias" (GUERRA, 2012, p. 2).

Angela Amaral (2012) também atenta para a nova relação que se estabelece entre o segmento empresarial e a pesquisa/pesquisador na pós-graduação brasileira:

O PNPG 2011-2020 propõe-se a favorecer a integração do ensino de pós-graduação com o setor empresarial e a sociedade. A formação de um ethos empreendedor entre os docentes (BOSI,

\footnotetext{
${ }^{16}$ Conforme Yolanda Guerra (2012, p. 2), esta lei (10.973/2004), de 2 de dezembro de 2004, complementada pela Lei do Bem (Lei $\mathrm{n}^{\circ} 11.196$, de 21 de novembro de 2005) - a qual, mediante a mera autodeclaração dos interessados, permite subvenção econômica e isenção fiscal às empresas que realizarem atividades de pesquisa visando à inovação tecnológica. É o exemplo típico do que é a pesquisa voltada a atender aos interesses da política industrial. Como se observa, não é casual que ela tenha plena vigência e ampla aceitação. Sobre a lei de inovação tecnológica, ver: <http://www.planalto.gov.br/ccivil_03/_at02004-2006/2004/ Lei/L10.973.htm>. Sobre a lei do bem: <http://www.p̄lanalto.gov.br/ccivil_03/_ ato2004-2006/2005/lei/l11196.htm>. Ambos acessados em $1^{\circ}$ ago. 2011.
} 
2009) é estimulada e passa a contar com suporte jurídico-legal para se configurar como parte da nova cultura acadêmica. A Lei de Inovação Tecnológica também prevê que a remuneração do docente tenha um adicional variável e outras vantagens, condicionados a sua inserção no mercado, na condição de empreendedor. O docentepesquisador, na perspectiva do PNPG, pode e deve, além de promover a inovação, participar da inserção do resultado de sua pesquisa no mercado produtivo. Esta compreensão, inclusive, já foi incorporada na proposta do MEC/MPOG, que trata da flexibilização da dedicação exclusiva (AMARAL, 2012, p. 233).

Esse processo expressa uma ameaça concreta ao que vem se construindo na pós-graduação em Serviço Social' ${ }^{17}$, considerando os compromissos ético-políticos assumidos com uma produção de conhecimento voltada a desvelar as contradições da sociabilidade capitalista, fortalecer sujeitos políticos com vistas a superá-la e construir mediações que tenham incidência na vida sócio-histórica.

\section{CARACTERIZAÇÃO DA ÁREA}

Neste contexto, percebe-se uma clara sintonia entre a política de educação voltada ao ensino superior, o PNPG (2011-2020) e as orientações introduzidas pelos governos neoliberais, que respondem às demandas da reestruturação capitalista contemporânea.

No que se refere aos cursos stricto sensu, as diretrizes gerais e metas atuais para os programas de pós-graduação no Brasil, previstas no PNPG, em 10 anos, giram em torno de eixos programáticos,

${ }_{17}$ A ameaça do redimensionamento do sistema nacional de avaliação para a pós-
graduação brasileira, posto pelo PNPG, é visível. AMARAL (2012) destaca que a
ênfase no tratamento dos temas como inter e multidisciplinaridade poderá
produzir análises fragmentadas e pontuais da realidade, uma marca tradicional/
técnica da pesquisa e da produção de conhecimento na profissão nos idos dos anos
de 1940 a 1970 , que em nada se assemelha ao conhecimento crítico alcançado com
a análise marxista dos objetos de pesquisa pelo Serviço Social a partir dos anos
1980, citados neste texto. Ainda destaca que o perfil produtivista de pesquisador,
crescente em outras áreas, vem influenciando o Serviço Social, estimulado
também pelas novas medidas postas pela Lei de Inovação Tecnológica. Os outros
temas, como inovação e internacionalização, vêm sendo demandados aos PPGs
e constam como elementos importantes na avaliação da área. A ameaça é real. É
preciso que os PPGsarticulados coma ABEPSS resistama essa lógica, considerando
as contradições que a constituem, e imprimam uma direção ao processo que
reafirme a qualidade acadêmica e a direção social estratégica da profissão. 
conforme citado, e dentre estes se destacam: interdisciplinaridade, internacionalização(incentivoaos Intercâmbios entre universidades brasileiras e os EUA, América Latina e Central e outros continentes), pós-graduação lato sensu a distância, mestrados profissionais ${ }^{18}$ interdisciplinares com financiamento público etc.

De acordo com a CAPES, o Serviço Social e a Economia Doméstica como área de conhecimento reúnem, na atualidade, 34 Programas de Pós-graduação (32 em Serviço Social e 2 em Economia Doméstica), com cursos stricto sensu acadêmicos - Mestrados e Doutorados - em todas as regiões do Brasil. Na sua maioria, 26 cursos (75\%) estão inseridos em instituições de ensino superior públicas/IES, seis (16\%) em instituições estaduais e dois (5,9\%) em instituições privadas. Essa concentração dos programas nas IES públicas explica a peculiaridade dessas universidades em articular a relação entre ensino, pesquisa e extensão, que possibilita ampliar a pesquisa integrada ao ensino da graduação e da pós-graduação.

Entre os cursos existentes, há 16 (47,1\%) com Mestrado/Doutorado e 18 (52,9\%) com Mestrado. Conforme destaca Boschetti (2014, p. 1), o crescimento dos programas demonstra o avanço da qualificação profissional, o que permite a abertura de novos cursos de Mestrado: três em universidades estaduais, sendo dois no Nordeste e um no Sul, atingindo regiões no interior do país que não têm tradição em pesquisa, possibilitando a qualificação de profissionais para a docência no ensino superior. A área básica desses programas está concentrada em Serviço Social e Política Social (ou Política Pública), e as áreas de concentração e linhas de pesquisa abordam temas como Serviço Social, Política Social, Estado, Direitos Sociais, Cidadania, Trabalho, Questão Social, Política Pública, Desenvolvimento Regional, Desenvolvimento Local, Movimentos Sociais.

É visível o crescimento desses programas nas duas últimas décadas, com a consolidação das pesquisas e da produção de conhecimento na área, o que se verifica na última avaliação do qualis livro no

\footnotetext{
${ }_{18}$ A ABEPSS assume coletivamente, em 2012, no ENPESS/UFJF, posicionamento contrário à delimitação de critérios específicos na ficha de avaliação da área, relacionados aos cursos de Mestrado Profissionalizante. Defende apenas sua incorporação na ficha, mantendo os critérios do Mestrado acadêmico.
} 
triênio (2010-2012), que totaliza 2.758 publicações, bem como o fortalecimento dos periódicos na área. No que se refere a avaliação final dos programas, aárea conquistou: um programa com pontuação 7, seis programas com conceito 6, dois PPGs com conceito 5, doze programas com conceito 4 e doze com conceito 3. Apesar do esforço empreendido pela área, ainda predomina uma assimetria entre os programas considerados de excelência e uma maioria com conceito 3 e 4, o que demanda o apoio e o investimento da ABEPSS para enfrentar esta tendência que expressa desigualdades regionais históricas no país, produto de sua heterogeneidade estrutural, e também das questões que articulam a graduação e a pós-graduação. Assim, cumpre superar a dificuldade de articulação respeitando as peculiaridades dos programas e buscando fortalecer a direção social estratégica da profissão.

\section{DESAFIOS À PÓS-GRADUAÇÃO EM SERVIÇO SOCIAL NO BRASIL}

Com o intuito de fortalecer a área para lidar com os impactos referidos neste documento e construir contratendências que operem com as contradições, o Grupo de Trabalho sobre Pós-Graduação reunido em 2014 conforme já citado, a Coordenação Nacional de Pós-Graduação/ ABEPSS (gestões 2013-2014 e 2015-2016) e o Fórum Nacional de Coordenadores de Pós-Graduação da ABEPSS em 2015 apontam desafios para a pós-graduação em Serviço Social a partir da reflexão dos resultados da última avaliação trienal da área.

\section{Solidariedade institucional}

Emtempos de estímuloao individualismo acadêmico è̀ competição, a partir do fomento pelas agências de um ethos gerencialista, de métricas e metas muitas vezes meramente quantitativas, cabe à ABEPSS o papel estratégico de estimular uma lógica de resistência na direção contrária, tendo em vista fortalecer a área de Serviço Social por meio de impulsos coletivos, de planejamento de articulações e projetos de largo prazo, divulgando junto aos programas os canais disponíveis nas agências, bem como criando espaços que propiciem a interlocução, o encontro dos programas e a troca de experiências no campo da pesquisa e da pós-graduação. É desta forma coletiva que as assimetrias regionais, que se refletem na avaliação dos programas, podem ser enfrentadas, na perspectiva de um avanço da área como um todo. O estímulo 


\section{temporalis aвeps}

pela ABEPSS à participação em editais de PROCADs, PROCADs/ Casadinhos, DINTER e MINTER, inclusive alguns editais que incluem a internacionalização - um eixo constitutivo da pós-graduação que será tratado adiante neste documento -, a exemplo de projetos integrados envolvendo o Brasil e universidades no exterior, é fundamental. Os projetos integrados de pesquisa, intercâmbio e de formação continuada de docentes/pesquisadores são os canais institucionais de solidariedade disponíveis mais importantes. A ABEPSS constitui uma referência para os programas a partir de outras iniciativas de estímulo à solidariedade e articulação entre os PPGs na área que podem gerar sinergias e frutificar iniciativas comuns, tais como:

- Os Grupos Temáticos de Pesquisa (GTPs) são um processo desencadeado em 2010 e atualmente em curso. Trata-se da constituição de redes de pesquisadores em torno de eixos temáticos que foram definidos coletivamente. Alguns GTPs estão mais avançados em sua consolidação, outros menos, mas o fato é que já há edições da Revista Temporalis organizadas com base nesta experiência e os dois últimos ENPESS vêm se organizando cada vez mais orientados por esta articulação. No nosso entendimento, os GTPs são uma estratégia privilegiada de solidariedade e de um bom combate ao individualismo e produtivismo acadêmicos.

- As Oficinas de Editores e Conselhos Editoriais de Periódicos da área são um espaço de troca importante para a consolidação dos periódicos, que permite o intercâmbio de experiências e a formulação de estratégias coletivas para lidar com as pressões e dificuldades, na perspectiva de consolidar periódicos de qualidade na área e racionalizar esse processo. Intenta evitar a fragmentação excessiva dos meios de publicação da produção científica na área, a partir do debate coletivo. A Revista Temporalis, de âmbito nacional e sob a responsabilidade da ABEPSS, torna-se então um meio estratégico, bem como as coletâneas temáticas, resultado de projetos integrados, dos GTPs e da articulação entre programas e pesquisadores. São meios interessantes para a ruptura do isolamento acadêmico e a consolidação de uma cultura de interlocução e solidariedade. 
- O fortalecimento do Fórum Nacional de Coordenadores de PósGraduação da ABEPSS, por meio da realização de reuniões ${ }^{19}$ previamente agendadas a partir da iniciativa da Coordenação Nacional de Pós-Graduação da ABEPSS, constitui-se como estratégia fundamental, pois é nesses momentos que aqueles que estão conduzindo os PPGs, com seus dilemas e grandes desafios, podem se encontrar para debater agendas comuns a partir da direção estratégica da ABEPSS. Nestes momentos, em geral, dá-se a presença das representações de área na CAPES e CNPq, o que propicia uma visão global dos processos de avaliação e de fomento, viabilizando traçar estratégias coletivas fundadas no princípio da solidariedade institucional entre os PPGs. Nestas ocasiões é possível mobilizar outros interlocutores institucionais e os movimentos sociais e movimento docente, tendo em vista enfrentar as tensões e conflitos que envolvem a pesquisa, a pós-graduação, enfim, a política de ciência e tecnologia num país de capitalismo periférico, com todos os significados que tal condição imprime a essas dimensões do ensino e da pesquisa, especialmente na área social, e muito particularmente em nossa área, considerando a direção social do projeto de formação na graduação e na pós-graduação. Esse diálogo também é central para que sejam traçadas estratégias coletivas que consigam de fato incidir no desenho da pós-graduação em Serviço Social no país, bem como na pós-graduação em geral.

\section{Articulação entre graduação e pós-graduação em Serviço Social}

A articulação entre a graduação em Serviço Social e os Programas de pós-graduação vinculados à área do Serviço Social na CAPES sempre foi objeto de debates e proposições nos eventos da área e constituiu um objetivo assegurado nas Diretrizes Curriculares para os cursos de graduação. A ênfase nesta articulação decorre do entendimento de que a formação no âmbito dos programas de pós-graduação constitui espaço privilegiado de pesquisa, mas também de preparação de profissionais docentes/pesquisadores para o ensino superior,

\footnotetext{
${ }_{19}$ Aproveitando inclusive a realização dos Seminários de Acompanhamento da CAPES, o que pressupõe o diálogo sistemático com aquela representação de Área.
} 


\section{temporalis aвpps}

voltado tanto para os cursos de graduação em Serviço Social quanto para os cursos de mestrado e doutorado da área. Nesse sentido, a articulação entre graduação e pós-graduação se revela necessária e estratégica para assegurar a formação com qualidade e comprometida com valores e princípios fundantes do Projeto Ético-Político Profissional, construído histórica e coletivamente pelo Serviço Social nas últimas três décadas, que teve no surgimento e na expansão da pós-graduação um espaço fecundo de germinação. A direção teórico-crítica das pesquisas e produções realizadas nos programas de pós-graduação foi, portanto, uma referência essencial para a formação em Serviço Social e para a possibilidade histórica de construção de um projeto profissional assentado na teoria crítica.

A expansão quantitativa dos Programas de pós-graduação da área foi seguida pela diversificação da área básica, o que ressalta a necessidade de sua articulação com a graduação em Serviço Social. Entre os 32 cursos da área de Serviço Social listados por área básica na página da CAPES, a maioria dos Programas de pós-graduação possui área básica em Serviço Social: 22 (68,7\%). Destes, quatro articulam Serviço Social e outros temas, o que indica a ênfase de suas pesquisas: Serviço Social e Desenvolvimento Regional, Serviço Social e Direitos Sociais, Serviço Social e Política Social, Serviço Social, Trabalho e Questão Social; entre os outros dez (31,3\%) Programas listados, sete são em Política Social (e destes um é em Política Social e Cidadania) e três são em Políticas Públicas (sendo um destes em Políticas Públicas e Desenvolvimento Local). Estas áreas básicas, bem como as áreas de concentração e linhas de pesquisa dos Programas, se conectam com temas e conteúdos historicamente abordados pelo Serviço Social brasileiro - Política Social, Estado, Direitos Sociais, Trabalho, Questão Social, Desenvolvimento. Isso pode indicar que estes Programas possuem preocupação em assentar conteúdos relacionados com a graduação, o que incide de forma positiva na formação acadêmica de docentes e/ou futuros docentes dos cursos de graduação em Serviço Social. Contudo, esta preocupação deve ser seguida pela afirmação de que tais conteúdos são imprescindíveis ao Serviço Social. Aos programas, cuja área básica é o Serviço Social, é imprescindível a relação direta e orgânica com os dilemas, possibilidades e limites postos a 
profissão e a sua agenda política. A ABEPSS defende a necessidade desta articulação, e o não distanciamento destes Programas dos conteúdos de fundamentação histórica, ética e política particulares da profissão, o que reforça a necessidade de construir estratégias de articulação que se pautem pelo compromisso de fortalecimento do Projeto Ético-Político Profissional.

Esse contexto coloca como desafio o incremento dessa articulação, que pode ocorrer por meio de diversas estratégias ${ }^{20}$, algumas mencionadas a seguir:

- Organização de fóruns regionais de graduação e pósgraduação com pauta e discussões unificadas;

- Investimento em núcleos e grupos de pesquisa que envolvam docentes e discentes de graduação e pós-graduação;

- Organização de eventos conjuntos voltados à apresentação de trabalhos científicos da graduação e pós-graduação;

- Investimento em veículos de divulgação da produção intelectual (livros, artigos, comunicações científicas) envolvendo docentes e discentes da graduação e pósgraduação;

- Envolvimento dos docentes e discentes com as pesquisas da Iniciação Científica/PIBIC;

- Realização de estágio de docência, o que possibilita a participação dos mestrandos e doutorandos em disciplinas no âmbito da graduação em Serviço Social;

- Implementação de atividades de extensão na graduação (Núcleos de extensão, PETs, grupos de pesquisa) que articulem graduação e pós-graduação.

Longe de esgotar as possibilidades de articulação, o que se quer enfatizar é a necessidade de incorporação, pelos programas de pós-graduação da área, sobretudo daquele cuja área básica é o Serviço Social, das Diretrizes Curriculares Nacionais da ABEPSS, ou seja, dos conteúdos referentes aos três núcleos da formação profissional e da direção social que a constitui. Sabe-se que

\footnotetext{
${ }^{20}$ As quatro primeiras estratégias compõem o Relatório do Primeiro Seminário organizado pela ABEPSS em 1999 para discutir a reforma do ensino superior e está publicado na Revista Temporalis 1, o que indica ser esta uma preocupação sempre presente nos debates da ABEPSS.
} 


\section{temporalis aвpps}

vários programas já viabilizam esse conhecimento, por meio de disciplinas que compõem os seus projetos pedagógicos. Contudo, é imprescindível assegurar a inclusão/fortalecimento de disciplinas ou atividades curriculares que abordem os fundamentos do Serviço Social e as matrizes teórico-metodológicas que as informam.

\section{Distinção entre produtivismo versus produção científica e o Sistema de Avaliação}

Este é um tema polêmico, que se agrava com a contrarreforma do ensino superior, posta pelas exigências/pressões do PNPG à pós-graduação brasileira. O movimento docente, através do seu sindicato (ANDES) vem investindo historicamente na denúncia contra todas as formas de produção acadêmica que desqualificam o ensino superior e escravizam/subordinam os docentes/ pesquisadores às métricas.

O Serviço Social é reconhecido socialmente como área de conhecimento, contudo precisa avançar mais e socializar sua produção acadêmica crítica, que se fundamenta na teoria social crítica que desvela as contradições da sociabilidade burguesa. Essa é uma necessidade da área, haja vista o compromisso social de sua pesquisa com as demandas da reprodução da classe trabalhadora e do projeto profissional crítico.

A ABEPSS compreende que produzir conhecimento remete ao domínio de teorias sociais, da dinâmica do desenvolvimento capitalista atual e da análise dos fenômenos sociais. Reconhece que a maioria da produção científica do Serviço Social brasileiro revela o empenho acadêmico de profissionais (docentes/ discentes) em pesquisar, qualificar a área e desvelar a sociabilidade contemporânea e os desafios para o Serviço Social. Salienta que o estilo e a dinâmica da pesquisa na área das ciências humanas e sociais demandam tempo e dedicação, e que a qualidade da produção requer uma análise criteriosa.

A entidade esclarece que o produtivismo, de modo distinto, corresponde à produção e à publicação desenfreada sem critérios de qualidade e seriedade acadêmica, apenas para responder às requisições quantitativas das agências de fomento, a partir de uma métrica artificial nos currículos. O produtivismo 
superficializa as produções, pois leva à produção descritiva de processos pela pressão dos resultados. O produtivismo tornase evidente na assinatura de artigos entre docentes e discentes indiferenciadamente, na repetição da publicação de textos que apresentam apenas título e alguns aspectos formais diferentes, na assinatura de textos que não foram elaborados por um dos autores, nas fraudes, expedientes que devem ser combatidos sem tréguas e que caminham na contramão dos princípios éticos que orientam a área. As implicações deste produtivismo desqualificam a área porque potencializam a concorrência entre os pares, fortalecem o individualismo e reafirmam a dimensão técnica no atendimento das exigências do padrão empreendedor do PNPG, bem como ampliam a assimetria entre os programas.

Assim, pesquisar e produzir conhecimento não é o mesmo que o produtivismo, visto que este responde a uma demanda tecnocrática e exclusivamente métrica. Como área de conhecimento o Serviço Social precisa ampliar com qualidade sua produção, diferenciandose do pressuposto quantitativo da lógica produtivista. Ao realizar tais considerações a ABEPSS não está formulando um instrumento de controle de qualidade, ao contrário, sugere aos programas o enfrentamento deste debate, sobretudo num momento em que os resultados da última avaliação trienal (2010-2012) indicam o avanço da produção acadêmica na área.

Deste modo, considerando os debates realizados na reunião do Fórum Nacional em 2015, os coordenadores presentes avaliaram que a existência do produtivismo tende a se fortalecer, tendo em vista que o sistema de avaliação da CAPES gera necessidades crescentes de produção aos programas e essas metas de produção são apropriadas geralmente pelas Áreas sem muitos questionamentos. Entende-se que tais metas não podem desconsiderar a realidade concreta dos Programas e as dimensões próprias da pesquisa social e a produção do conhecimento na nossa Área.

O Serviço Social brasileiro conseguiu desenvolver criticamente a pesquisa científica diferentemente do que vem ocorrendo com a profissão em outros lugares do mundo. Esta é uma particularidade brasileira que precisa ser considerada e é visível na produção de teses, dissertações, dos diversos Núcleos de Pesquisas e periódicos. 


\section{temporalis aвeps}

Toda essa produção tem fortalecido o Serviço Social como área do conhecimento.

Assim, apesar de entendermos que avaliação a qual submete os programas de pós-graduação e a produção do conhecimento sejam diferentes, tais aspectos estão diretamente vinculados a qualidade do que é produzido.

Com relação especificamente ao sistema de avaliação da CAPES, entendemos que a avaliação precisa dar conta da realidade dos vários programas, em termos locais, regionais, natureza da instituição mantenedora (cursos ofertados em IES Federais, estaduais e Municipais e particulares) e ainda pelo perfil e as exigências da consolidação no sistema nacional de pós-graduação (CAPES, CNPq).

$\mathrm{Na}$ atualidade, a avaliação tanto na graduação quanto principalmente na Pós-Graduação vem ocorrendo na perspectiva da punição e de forma instrumental e isso gera uma profunda angústia e preocupação entre os coordenadores de programas de pós-graduação, estudantes e professores envolvidos com a produção do conhecimento, tendo em vista o corte das bolsas, os rebatimentos na produção do conhecimento no Serviço Social, uma vez que a sua realidade é marcada pelo perfil dos estudantes, predominantemente alunos trabalhadores.

O Serviço Social não é contrário a existência de um sistema de avaliação, mas é necessário que este seja construído em conexão com as particularidades da profissão, que não se submeta às concepções de pesquisa existentes em outras áreas do conhecimento. Afirmamos que os critérios atuais de avaliação da pós-graduação, de um modo geral centrados no produtivismo, editais de financiamento e demandas do mercado, são incompatíveis com o Serviço Social e seu projeto de formação profissional e éticopolítico. Nossa Área deve unir-se na construção de parâmetros particulares de avaliação, com critérios construídos coletivamente pela categoria, coordenado pela ABEPSS e as representações do Serviço Social junto a CAPES e CNPq.

\section{Internacionalização da área}

Os debates realizados no Fórum Nacional de Coordenadores de Pós-Graduação em 2015 apontam que, em primeiro lugar, a 
internacionalização se põe como uma necessidade do Projeto Ético-Político Profissional do Serviço Social e neste, do projeto de formação profissional. Assim, perseguir a internacionalização nas ações não deve se justificar apenas em função das exigências das agências de fomento, como a CAPES, mas significa envidar esforços no sentido de fortalecer nossa direção social estratégica, crítica, com claro posicionamento de classe e vinculada a defesa de valores emancipatórios. As ações de internacionalização tendem a favorecer-nos neste sentido.

Em segundo lugar, é necessário se entender que o processo de internacionalização resulta das iniciativas constituídas por vários programas de pós-graduação da Área que envolve um conjunto de ações, como a realização de projetos de pesquisa com universidades estrangeiras, a publicação de artigos e livros compartilhados e como frutos de tais pesquisas, as inserções de nossos pesquisadores em grupos de pesquisa e a afirmação de convênios. Assim, as tentativas de cooperações e intercâmbios são importantes e podem se potencializar como estratégias para o aprofundamento da internacionalização dos programas, mas não podem ser entendidos como similares, pois esta supõe a existência de projetos e produções acadêmicas compartilhadas.

Deste modo, a internacionalização é resultante da solidariedade entre programas e grupos de pesquisa de países distintos, cujo objetivo é a produção de conhecimentos, bem como a ampliação e a qualificação do debate acadêmico e da pesquisa. É sabido que o Serviço Social brasileiro consolidou uma produção intelectual densa e crítica que é referência para vários países, especialmente para Portugal e países da América Latina, com destaque para a Argentina, ainda que não exclusivamente, o que influenciou a vinda de docentes/ pesquisadores e discentes para se qualificarem no Brasil. Observa-se que a mesma direção se aplica também a relação estabelecida com cursos de Serviço Social e grupos de professores de Costa Rica.

É bom lembrar que foram os brasileiros que implantaram em Portugal e na Argentina os primeiros cursos de pós-graduação em Serviço Social. O marco decisivo e simbólico dessa cooperação foi o primeiro curso de Mestrado em Portugal na Área, em fevereiro de 1987, no Instituto Superior de Serviço Social de Lisboa (ISSSL), 


\section{temporalis aвpps}

sob a responsabilidade e orientação científica da PUC-SP. Uma década depois foi criado no mesmo ISSSL o primeiro Doutorado, ainda sob a responsabilidade da PUC-SP. Como resultado dessa forte cooperação houve, até 2006, a titulação de 41 mestres e dez doutores no ISSSL, e 13 mestres e três doutores no Instituto de Serviço Social do Porto (ISSSP), outro parceiro no primeiro intercâmbio para a formação de mestres e doutores em Portugal. Outros resultados significativos devem ser mencionados na consolidação desse processo: a criação em Lisboa, em 2001, do Centro Português de Investigação e História em Trabalho Social, sob a direção da Dra. Alcina Martins (primeiro centro de pesquisa em Serviço Social português); a criação da Revista Intervenção Social e de outras publicações, entre as quais a Coleção Estudos Comparados Brasil/Portugal (primeira da área no país). Outros acordos - de 2006 a 2013 - levaram à oferta de cursos de pósgraduação em Serviço Social no Instituto Superior Miguel Torga, em Coimbra, e na Universidade Lusófona de Portugal (Lisboa e Porto), além de uma parceria com o Centro de Estudos Sociais (CES) da Universidade de Coimbra. Esses e outros convênios subsequentes foram de fundamental importância para o desenvolvimento do Serviço Social português e para a consolidação da política de intercâmbio entre o Serviço Social brasileiro e o português.

Com a Argentina o primeiro acordo na área do Serviço Social ocorreu em 1996, resultando na criação do primeiro mestrado e do primeiro doutorado em Serviço Social na Argentina. A universidade parceira foi a Universidade Nacional de La Plata (UNLP), onde foram titulados inicialmente 17 mestres e 12 doutores em Serviço Social da Escola de Serviço Social. Também na Argentina foi criada uma revista institucional, a Revista Escenarios da UNLP, que tem até hoje circulação regular. A parceria continua de outras formas. Atualmente, três docentes brasileiros, através de Acordo de Cooperação Acadêmica, participam do Comitê Científico dos cursos de Mestrado, Doutorado e da Especialização oferecidos pela UNLP na área de Serviço Social.

A internacionalização acontece no contexto do movimento de renovação profissional brasileiro, o que propiciou o avanço de uma perspectiva critica de análise do desenvolvimento capitalista contemporâneo e da própria profissão, contribuindo para a 
socialização de uma direção social estratégica de profissão. Como já apontado, em sua maior parte o processo de internacionalização se concentrou entre Brasil e demais países da América Latina. Atualmente esse processo envolve mais intensamente a França, a Itália e a Espanha. Com a França, na Universidade Pierre Mendes France (UPMF) de Grenoble, o Brasil (PUC-SP) mantém um mestrado conjunto, com dupla titulação, nas áreas de Avaliação e Gestão de Políticas Sociais (Grenoble) e Serviço Social (Brasil).

Convém esclarecer que há diferenças da formação/produção intelectual do Brasil em relação à Europa e EUA, mas vêm ocorrendo modificações que evidenciam o deslocamento de posições teóricometodológicas na Europa, EUA e África tendentes a aproximar e concretizar o intercâmbio crítico e produtivo intelectualmente entre o singular projeto profissional brasileiro e o mundo. Com a África, e especialmente com Angola, além de oferecer cursos para a qualificação do ensino de graduação em Serviço Social, o Brasil formou o primeiro doutor e alguns mestres angolanos em Serviço Social e vem participando de projetos no sentido da construção de Políticas Sociais nesse país em diferentes áreas. Além de Angola, destaca-se também a aproximação crescente com outros países africanos, como Moçambique, dentre outros, que vem recebendo a contribuição brasileira em seus cursos de Serviço Social através da incorporação inclusive de autores brasileiros em suas referências bibliográficas.

A ABEPSS apoia e incentiva o processo de internacionalização recomendando que este se amplie por meio da interlocução entre programas de excelência-que possuem condições mais consolidadas para deflagrar processos de internacionalização -, mas buscando envolver programas com pontuação igual ou inferior a 5 nas mais diferentes formas: ida e vinda de docentes/discentes em processo de ensino e de qualificação, como cursos de mestrado, doutorado e de pós-doutoramento; realização de pesquisas integradas de intercâmbio internacional; produção intelectual publicada em periódicos e coletâneas; realização de eventos internacionais etc. Tais experiências vêm, principalmente, acontecendo em programas notas 5 e 6 . O entendimento é que, de fato, as melhores condições estão aqui concentradas, mas que é possível desencadear, também neste âmbito, a solidariedade institucional. 


\section{temporalis aвpps}

Entende-se que é necessário se enfrentar as barreiras linguísticas, buscando a aproximação com o mundo anglo-saxão para disseminar e compartilhar a perspectiva teórico-metodológica e ético-política do Serviço Social brasileiro. Sugere-se, portanto, o investimento na superação do limite do domínio da língua inglesa na área, através do fomento da leitura da produção inglesa nos programas, tendo em vista uma aproximação com segmentos críticos no Serviço Social mundial. Nesta direção, devemos considerar a presença do Radical Social Work em alguns países e a possibilidade de aproximação com estes profissionais e pesquisadores na resistência à definição de Serviço Social formulada e veiculada pela Federação Internacional de Trabalho Social (FITS).

Destaca-se ainda que há uma predominância de intercâmbios (estágios sanduíches, pós-doutoramento) em países de língua portuguesa, espanhola, francesa e italiana, que são extremamente profícuos e devem ser mantidos, porém buscando-se ampliar o universo linguístico e cultural dessa interlocução (países anglosaxões e outros).

A ABEPSS reconhece e destaca que a área vem realizando ações na direção da internacionalização, mas ainda não de forma suficiente para consolidar uma rede de pesquisadores, pesquisas e intercâmbios na formação em conjunto fora do país. Além disso, tais ações ainda se concentram junto aos programas de pósgraduação com notas 6 e 7. Assim, propõe que os GTPs contribuam para construir redes de articulação nacional e internacional que subsidiem/impulsionem ações no âmbito da internacionalização. Por fim, sem descuidar de iniciativas que fortaleçam e atendam a demandas de solidariedade dentro do país, a entidade ressalta a importância do processo de internacionalização da área, que corresponde a $5 \%$ do peso da avaliação geral dos programas.

\section{Elementos gerais para discussão nos Programas de Pós- Graduação}

Com base na avaliação trienal (2010-2012), a entidade promove uma reflexão dos desafios da Pós-Graduação em Serviço Social, tendo em vista contribuir com o fortalecimento da área e com a reafirmação da direção social crítica da formação profissional. 
Neste contexto, a entidade aponta elementos gerais que fazem parte do processo de avaliação da área, para serem discutidos de forma permanente e coletivamente:

- Os critérios de avaliação dos PPGs, contidos na ficha, devem ser continuamente analisados com a coordenação de área da CAPES, com os coordenadores dos programas e com a ABEPSS, para avançarmos em termos de estratégias para a próxima avaliação quadrienal, iniciada em 2013 (2013-2016).

- Dada a tendência, na nova avaliação, de ser considerada apenas parte da modalidade de produção e publicação em eventos nacionais e internacionais, sugere-se o debate coletivo na área. Esta alteração poderá trazer um impacto para a pós-graduação em Serviço Social, porque a publicação nesta modalidade é representativa e, também, pelas perdas em relação ao processo de socialização das pesquisas e do debate acadêmico propiciados nos eventos, com destaque para o ENPESS e o CBAS.

- No que se refere ao corpo docente permanente e colaborador dos programas, a entidade apoia as iniciativas que discutam o perfil de ambos e como participam do processo de avaliação, com base, inclusive, na portaria da CAPES de novembro de 2011. Sabe-se que a produção intelectual do quadro permanente é decisiva na avaliação dos programas; assim a área precisa pensar uma estratégia coletiva que valorize o papel do professor colaborador e sua produção no processo de avaliação. Pela relevância desse aspecto, a entidade propõe que seja considerado o conjunto da produção docente, podendo-se estabelecer um peso maior para o corpo permanente em função de sua centralidade. De modo similar, entende-se que na avaliação de livros deva ser considerado o conjunto da produção do programa, ou seja, a produção do corpo docente permanente, dos colaboradores e dos discentes.

- A entidade recomenda que sejam debatidas coletivamente estratégias para enfrentar as dificuldades referentes ao tempo de titulação/conclusão dos alunos bolsistas, principalmente nos cursos de Mestrado, já que este não é um problema para as demais áreas. 


\section{temporalif asepss}

- Devido à importância do relatório anual (Plataforma Sucupira) para a avaliação da área, a ABEPSS recomenda o registro claro e objetivo das atividades realizadas pelos Programas para que sejam explicitadas qualitativamente as informações e os avanços alcançados. A entidade e o GT solicitam à coordenação de área na CAPES a elaboração de orientações para a criação de cursos em nível stricto sensu em Serviço Social. E que também, em prosseguimento às atividades desta representação, propicie o debate dos critérios da avaliação junto aos programas, ressaltando quais as implicações para a área.

Natal, outubro de 2014. ( $1^{\mathrm{a}}$. edição do Documento) Rio de Janeiro, novembro de 2015. ( $2^{\mathrm{a}}$. edição do Documento)

GT Pós-Graduação ABEPSS, Coordenação Nacional de PósGraduação da ABEPSS (gestões 2013-2014 e 2015-2016) e Fórum Nacional de Coordenadores de Pós-Graduação da ABEPSS

\section{REFERÊNCIAS}

ABEPSS. Temporalis, Brasília (DF), ano 4, n. 7, jan.jjun. 2003.

AMARAL, Angela S. do. A política nacional de pós-graduação e suas relações com o Serviço Social. Katálysis, Florianópolis, v. 15, n. 2, p. 230-238, jul./dez. 2012.

ANTUNES, Ricardo. Os sentidos do trabalho: ensaio sobre a afirmação e negação do trabalho. São Paulo: Boitempo, 1999. BOSCHETTI, Ivanete Salete. Proposta de atuação e plano de atividades: Coordenação de Área de Serviço Social e Economia Doméstica - CAPES. Brasília (DF), 2014. 
CAPES. Plano Nacional de Pós-Graduação (PNPG 2011-2020). Brasília (DF), 2010. 2 v. I/ Il.

GUERRA, Yolanda. A polêmica sobre o mestrado profissional e a área de Serviço Social: subsídios à reflexão. Rio de Janeiro, 2012. (Mimeo).

KOIKE, Maria Marieta. Formação profissional em Serviço Social: exigências atuais. In: SERVIÇO Social: direitos sociais e competências profissionais. Brasília (DF): Especialização CFESS, 2009.

LEHER, Roberto. A (contra-) reforma universitária do governo lula e o fim das fronteiras entre o público e o privado (Prefácio). In: NEVES, Lúcia M. W. (org.). Reforma universitária do governo Lula: reflexões para o debate. São Paulo: Xamã, 2004. p. 13-22.

LIMA, Kátia R. de S. Reforma da política educacional brasileira: a submissão do Governo Lula às políticas dos organismos internacionais do capital. In: PAULA, Maria de Fátima (Org.).

Debatendo a universidade: subsídios para a Reforma Universitária. Florianópolis: Insular, 2004. p. 25-42.

MÉSZÁROS, Istvan. Para além do capital: rumo a uma teoria da transição. São Paulo: Boitempo; Campinas: Unicamp, 2002. p. 605629.

NETTO, José Paulo. Ditadura e Serviço Social: uma análise do Serviço Social no Brasil pós-64. São Paulo: Cortez, 2007.

NETTO, José Paulo. Transformações Societárias e Serviço Social: notas para uma análise prospectiva da profissão no Brasil. Serviço Social \& Sociedade, São Paulo, n. 50, 1996.

SCHARTZMAN, Simon. Notas sobre a transição necessária à pósgraduação. Brasília (DF), 2010. (Mimeo.)

YAZBEK, Maria Carmelita; MARTINELLI, Maria Lúcia e RAICHELLIS, Raquel. O Serviço Social brasileiro em movimento: fortalecendo a profissão em defesa dos direitos. Serviço Social \& Sociedade, São Paulo, n. 95, p. 5-32, 2008. 